\title{
Leonilda Barrancos: una educadora de avanzada en la contradictoria Córdoba de las décadas de 1920 y $1930^{1}$
}

Fecha de recepción: 12 de diciembre de 2018. Fecha de aceptación: 21 de julio de 2019

\begin{abstract}
Resumen
Leonilda Barrancos vivió en Córdoba no más de dieciséis años dejando una huella que aún no se ha explorado suficientemente. Venía de un batallar bastante intenso en el área docente en Buenos Aires, donde integró la Liga Racionalista Argentina trabajando al lado de destacados maestros como Julio Barcos. Los principios de la Escuela Activa fueron la guía de su accionar, convirtiéndose en una persona crítica de la pasividad en que se mantenía a los alumnos, la exagerada memorización, el verbalismo y especialmente de la falta de adecuada preparación de los docentes.
\end{abstract}

Palabras clave: educación; psicología; Escuela Activa; pedagogía.

\begin{abstract}
Leonilda Barrancos lived in Córdoba not more than sixteen years leaving an imprint that surely has not yet explored sufficiently. She came from a fairly intense battle in the teaching area in Buenos Aires, where she joined the Argentine Rationalist League working alongside prominent teachers like Julio Barcos. The principles of the Active School were the guide of its actions, becoming a critical person of the passivity in which students were maintained, exaggerated memorization, verbalism and especially the lack of adequate preparation of teachers.
\end{abstract}

I Key Words: Education; Psychology; active school; Pedagogy.

1 Este trabajo en su primera versión fue presentado en las "Primeras Jornadas de la Red de estudios sobre el socialismo argentino (RESA)" realizadas en Buenos Aires en diciembre de 2016. Fueron tenidos en cuenta los comentarios y sugerencias realizados por Andrés Bisso, a quien agradecemos profundamente. 


\section{Introducción}

Pensando en la Argentina de fines del siglo XIX y comienzos del XX, y tal vez desde un poco antes y hasta mucho después, es bastante "natural" que una mujer escogiera la carrera docente para su itinerario laboral y vital. ${ }^{2}$ No obstante, esta afirmación merece algunas notas explicativas. Para comenzar diremos que el acceso al mundo del trabajo de las mujeres es un tema dentro de la historiografía de mujeres en permanente revisión y, como dicen Caldo y Vignoli (2016) "es (...) producto de la decisión militante de visibilizar la agencia femenina en los procesos históricos". La llegada de las mujeres al ejercicio de la docencia no ocurrió por un camino llano y accesible sino que, como en tantos otros casos, fue un recorrido por un terreno de disputa con el mundo masculino en donde la conquista de puestos de trabajo se dio gradualmente desde la práctica docente áulica y más tardíamente con el arribo a puestos de mayor jerarquía. Hacia fines del siglo XIX, la tarea docente se fue feminizando, y halló su justificación en el imaginario de la época que adjudicaba a las mujeres ciertas condiciones como "la abnegación, el sacrificio, la paciencia, el altruismo, la espiritualidad..." (Billorou, 2016: 64). Fiorucci (2016: 122) coincide con esta postura y menciona algunas características que dan cuenta de la feminización de la tarea docente: un imaginario que atribuía cualidades intrínsecas de las mujeres - ternura, paciencia, apego a la tradición-que las harían más aptas que los hombres para la tarea docente, unido esto a la función maternal; la elevada necesidad de docentes que hacía difícil cubrir los cargos con personal masculino; la cuestión económica del menor costo laboral de las mujeres; la idea de una mayor fidelidad a la profesión, que no se daba entre los hombres porque tenían más posibilidades de encontrar oportunidades de trabajo dentro de un mundo patriarcalmente normado.

Pretender analizar la trayectoria de Leonilda Barrancos en Córdoba, ese relativamente corto retazo de su vida, nos ha puesto ante preguntas tal vez insoslayables a la hora de abordar la biografía de una persona pero que, a su vez, es necesario recortar de un universo casi ilimitado: ¿quién fue esa mujer? ¿Qué circunstancias especiales determinaron la elección de su carrera? ¿Cuánto incidió su entorno y/o su determinación personal para establecer los derroteros que escogió? ¿Por qué su figura ha permanecido en el ostracismo durante tanto tiempo? Haremos la salvedad de que tanto las preguntas que nos formulemos, como las respuestas que ensayemos y los argumentos que esgrimamos a la hora de la fundamentación tienen que ver con un posicionamiento frente a los acontecimientos históricos y al rol que asignamos a los sujetos intervinientes. Adscribimos a una postura (Bolufer Peruga, 2008: 16) que evite encasillar, en este caso a una mujer, en estructuras socioeconómicas determinantes como lo hacía la historia social tradicional o dejarla atrapada por sus discursos al modo de los planteos de la historia cultural. Antes bien, reflexionamos sobre el grado de aceptación que tienen mujeres y hombres a las normas impuestas por la sociedad de su época, rescatando la capacidad de agencia de las/os mismas/os que las/os convierte en hacedoras/es de su propio destino. Esta mirada deviene en altamente compleja y riesgosa porque obliga al historiador/a a introducirse en la subjetividad del personaje para observar, también en nuestro caso, la forma en que ha sido capaz de otorgar sentido a los modelos vigentes, a interiorizarlos, a negociarlos o rechazarlos, todo ello a la vista de unos indicios ${ }^{3}$ más o menos limitados: relaciones sociales y laborales, algunos escritos, escasas noticias aparecidas en la prensa.

En esta indagación biográfica en que nos estamos adentrando, carecemos de algunas fuentes que serían muy útiles y significativas, como por ejemplo todo lo relacionado 2 Las opciones eran harto escasas y era sacrificado para una joven del interior, aunque fuera de la provincia de Buenos Aires, ya que el número de establecimientos dedicados a la formación docente era reducido y todavía menos eran las instituciones que formaban para desempeñarse como profesoras/es.

3 Con este término nos referimos al seguimiento, bastante pobre por cierto, con que hemos podido documentar el paso de Leonilda por Córdoba. 
con el arsenal de las comunicaciones personales: cartas, tarjetas, diarios de viaje o diarios íntimos, memorias o fotografías, relacionadas con este período de la vida de Leonilda, que no hemos podido ubicar. En principio atribuímos esta ausencia a dos circunstancias que podrían estar ligadas entre sí: una tiene que ver con razones de índole personal - lo cual de inmediato lleva al interrogante ¿cuán personal es lo "personal"? - como llevar una vida en cierta manera errante, con mudanzas desde el punto de vista físico y se podría resumir en clave enumerativa: nació en Mercedes, estudió en Paraná, vivió en Buenos Aires, se trasladó a Córdoba, probablemente otra vez Buenos Aires, Santiago de Chile, Buenos Aires, Caracas (?), México, Santiago de Cuba, finalmente Buenos Aires. La otra circunstancia se relaciona con el género, y el cono de sombra que se extiende sobre las mujeres, una zona oscura de la cual, como reproducimos más arriba, solo una actitud militante podrá sacarlas.

El género biográfico - al que adscribiríamos en este artículo-, al decir de Arfuch, ha tomado nueva consistencia en la posmodernidad con "la crisis de los grandes relatos legitimantes, la pérdida de certezas y fundamentos (de la ciencia, la filosofía, el arte, la política), el decisivo descentramiento del sujeto y, coextensivamente, la valorización de los 'microrrelatos', el desplazamiento del punto de mira omnisciente y ordenador en beneficio de la pluralidad de voces, la hibridación, la mezcla irreverente de cánones, retóricas, paradigmas y estilos" (2002 18). Otra noción central para nuestro trabajo es la de la relación entre lo público y lo privado, donde se ha demostrado la inexistencia de una dicotomía entre ambos, más bien estaríamos frente a una complementariedad o en un espacio intermedio entre los dos "que clausura la antinomia, revelando la imbricación profunda entre individuo y sociedad" (ibídem: 248). Así, la biografía personal se convierte en un asunto público en la medida en que el sujeto produce hechos que entran en la esfera de lo comunitario y de las responsabilidades compartidas con otros/as. Tanto la autora que estamos siguiendo como Bolufer Peruga (2008: 194) abordan la construcción de la privacidad, en los albores de la modernidad, como un espacio íntimo, restringido, el ámbito de la conciencia individual relacionado dialécticamente con la construcción en paralelo del espacio público identificado con el mundo de una sociabilidad amplia, con el Estado y, más tarde, con la "opinión pública". Imposible pensar uno sin el otro y, menos aun, uno contra el otro.

En cuanto a la trayectoria de Leonilda Barrancos en Córdoba, vamos a tomar dos aspectos enlazados entre sí pero cada uno con su propia especificidad: desde el punto de vista centrado en lo laboral su desempeño como docente -aunque más concretamente como pensadora del acto educativo-y desde el punto de vista de la sociabilidad y lo político, su pertenencia a un ámbito ligado a la intelectualidad cordobesa que a su vez se vinculaba con otras provincias argentinas e incluso con otros países latinoamericanos. Tal como menciona Caldo (2018) al hablar de Herminia Brumana y de Olga Cossettini, Leonilda también dejó de ser solo reproductora de saberes para ubicarse como productora y divulgadora de conocimientos. Su compromiso, al igual que el de aquellas maestras, excedió la experiencia áulica y, en su caso, penetró de lleno en las reflexiones acerca del sistema educativo argentino apuntando en forma particular a la formación de los docentes. ${ }^{4}$ En cuanto al ámbito de la sociabilidad, en las décadas de 1920 y 1930 surgieron en Córdoba y en muchos lugares de la Argentina, agrupaciones diversas de adhesión a alguna causa o como manifestación de protesta por determinada situación particular. Detrás de las siglas, de los agrupamientos, siempre hay alguien con nombre propio, en nuestro caso Leonilda Barrancos, docente que cuando arribó a Córdoba en 1921 ya había acumulado experiencia en trabajos colectivos, tal como veremos.

4 Hacemos referencia aquí a dos producciones de Leonilda en su período de estancia en Córdoba y que analizaremos en el curso del artículo: una es la publicación en la Revista de la Universidad Nacional de Córdoba y otra, de mucha menor envergadura, es el comentario de su conferencia en Santiago del Estero. 
El objeto del presente trabajo es indagar sobre los pasos seguidos por esta joven mujer en su permanencia en Córdoba, lugar no elegido por ella sino impuesto por la circunstancia de su matrimonio con Gregorio Bermann. Pero así como no eligió este lugar para vivir, tampoco se adaptó dócilmente a una sociedad harto conservadora que reservaba prioritariamente lugares domésticos para las mujeres. Lejos de ello, vamos a encontrarla formando parte del espacio público en actividades diversificadas: la profesión que ya había asumido, la docencia secundaria; la adscripción, en clave solidaria y marcadamente política, a grupos de ayuda primero al pueblo ruso y luego al pueblo español; la protesta frente a la arbitrariedad del gobierno argentino al deportar al exiliado boliviano Tristán Marof (acontecimiento subsecuente de la guerra del Chaco); la difusión de sus ideas pedagógicas a través de conferencias y artículos.

A modo hipotético podemos decir que ella era portadora de una rica experiencia aquilatada en el contacto con quienes integraban la Liga Racionalista Argentina donde había trabajado con destacadas personalidades. En principio, el ambiente de Córdoba no le ofreció muchas alternativas de despliegue de sus actividades y más bien se dedicó al trabajo docente y a los primeros años de crianza de sus hijos. Pero hacia el final de la década de 1920, y particularmente después de su viaje por Europa, su figura se hizo más visible en la esfera pública y fue estableciendo otros contactos y relaciones que la llevarían en años siguientes a realizar diversas experiencias de viaje y de trabajo por diferentes países de América Latina.

\section{Acerca de Leonilda Barrancos}

Leonilda Irene Barrancos nació en Mercedes, partido homónimo, en la provincia de Buenos Aires, el 12 de febrero de 1890. Pertenecía a una familia cuyos antecesores fueron inmigrantes españoles radicados en la zona de Luján-Mercedes-Chivilcoy desde el siglo XVIII, antiguos propietarios de tierra, incluso enfiteutas. Fue la primera de los siete hijos del matrimonio de Pedro José Barrancos y Jacinta Fernández Rivarola. ${ }^{5}$

Seguramente hizo los estudios correspondientes al magisterio en la Escuela Normal de Mercedes fundada en 1887. El pedagogo Carlos Norberto Vergara fue el primer director de esta institución y un auténtico innovador en métodos de enseñanza. Partía de una concepción de la niñez totalmente diferente a la propuesta positivista predominante en la constitución del sistema educativo argentino. Lejos de reprimir los impulsos infantiles, pensaba que era necesario resignificarlos y convertirlos en el motor del proceso de aprendizaje, valorando y poniendo en primer plano la autonomía del niño. Uno de los aspectos que, a nuestro entender, más resistencia generaba en los sectores de poder, era sostener que "la opresión adulto-niño y maestro-alumno formaba parte de un sistema global de opresiones que afectaban (...) la relación entre Estado y pueblo, nación y provincias y aun la relación entre América Latina y los países europeos" (Carli, 2002: 126). Otro aporte muy importante sobre el caso Vergara informa que desenvolvió su actividad en una época en que "el trabajo pedagógico fue orientado hacia la codificación y homogeneización de la cultura escolar, con el fin de "construir' un sujeto pedagógico homogéneo". Esta, obviamente, era la propuesta de un Estado en construcción hacia fines del siglo XIX. Es interesante la observación de que la historiografía tradicional ha reconocido que la construcción del sistema educativo argentino fue objeto de luchas al interior de los sectores hegemónicos, en particular entre sectores liberales y católicos, afirmando que ese par dicotómico dejaba afuera otras numerosas posturas que fueron menos estudiadas. Ellas serían "alternativas pedagógicas que no pueden ser subsumidas en las categorías 'liberal' o

5 Los datos de filiación han sido tomados de la partida de nacimiento archivada en la Escuela Normal de Paraná. También en Tarcus (2007: 47-48). 
"católica". La propuesta de Vergara en la Escuela Normal de Mercedes, tan combatida en su momento, sería un caso marginal al debate más difundido (Terigi, 1998: 226). Vergara fue partidario de aplicar una verdadera desburocratización en la educación, rompiendo los moldes disciplinarios, programáticos y organizativos típicos del normalismo de la época fuertemente influenciado por el positivismo. Su experiencia en este establecimiento tuvo corta vida ya que en junio de 1890 fue exonerado del cargo tras una inspección que no comulgaba con tanta autonomía. Pero Vergara era apreciado en la comunidad y seguramente lo vivido en esos años iniciales de la escuela dejó sus huellas en los docentes que lo acompañaron y los allí formados. Es muy probable que cuando Leonilda cursó la primera parte de sus estudios secundarios, el director de la Escuela Normal de Mercedes fuese Víctor Mercante, situado en las antípodas del pensamiento escolanovista al que después ella adhirió. ¿Conoció Leonilda la experiencia cuasi libertaria de Vergara en su Mercedes natal? ¿Eligió continuar sus estudios en la Escuela Normal de Paraná porque allí también había estudiado Vergara? ${ }^{6}$ ¿Por qué no cuajó en ella el pensamiento positivista de su nuevo director?

Para comprender mejor por qué Leonilda tuvo que mudarse de escuela diremos que según el Plan de Estudios de 1886 (Alliaud, 2007: 190-194), se instituían dos clases de escuelas normales: las Elementales, que formaban maestros/as de escuela elemental y las Superiores que complementaban la anterior formación con la preparación de profesores/as que enseñarían en las escuelas normales. Con el interés de conseguir este segundo título fue que Leonilda obtuvo una beca del gobierno nacional ${ }^{7}$ para completar quinto y sexto año en la escuela Normal de Paraná en los años 1910 y 1911. Obtuvo allí su título con excelentes calificaciones tal como se observa en el apéndice documental que acompaña este trabajo. El vacío de fuentes con que tropezamos para seguir los pasos de Leonilda solo nos permite hablar en términos de conjeturas, ${ }^{8}$ pero no nos impide asegurar que esos años dejaron profundas huellas en su formación ya que de la escuela Normal de Paraná se ha dicho:

De ella egresarían los primeros maestros normalistas argentinos: centro de producción de maestros-pedagogos, maestros políticos de la educación, maestros fundadores de escuelas normales y de escuelas primarias en todo el país. Los normalistas egresados de Paraná se dispersaron por todo el país marcando su impronta en la alfabetización de la población nacional y extranjera; sin embargo la ideología pedagógica transmitida no fue homogénea. (Ossanna y López, 2004:396)

Los gobiernos conservadores que dominaron la escena política argentina en la segunda mitad del siglo XIX y comienzos del XX fueron en cierta manera permeables a la presencia de las corrientes del pensamiento europeo de aquella época con todas sus variantes liberalismo, anarquismo, socialismo las que estuvieron presentes en la educación oficial argentina. De hecho, muchos docentes, inspectores y funcionarios de la educación pública no ocultaban sus ideas radicalizadas, aunque en algunos casos les valió la persecución y hasta la exoneración.

6 Uno de los maestros que tuvo Vergara fue el pedagogo Pedro Scalabrini, a quien recuerda en sus obras y cuya metodología de trabajo centrada en la experimentación por parte de los alumnos rescató constantemente. Disponible en: https://www.youtube.com/watch?v=wr319/mHhCw.

7 Obra en el archivo de la Escuela Normal de Paraná la autorización de Pedro Barrancos para que su hija estudie magisterio. En caso de no completar dichos estudios tendría que reembolsar el importe de la beca.

8 Al decir de Dora Barrancos, sobrina de Leonilda, haber cursado el magisterio en la Escuela Normal de Paraná ya es toda una definición. Ella señala que quien tomó esa decisión fue su padre que tenía ideas progresistas para la época y seguramente eligió para su hija primogénita el colegio más renombrado del normalismo argentino (entrevista hecha por la autora a D. B. el 05/08/2016). Agregamos que es harto probable que intervinieran otras variables en la decisión de Leonilda, tal como tratamos aquí de demostrar. 
Luego de su egreso de la escuela normal de Paraná, Leonilda se radicó en Buenos Aires entrando enseguida en contacto con los sectores más contestatarios del magisterio porteño. Puiggrós (2006) la ubica como adherente a los principios de la Escuela Activa cuyos integrantes también fueron pioneros en la defensa del sindicalismo docente. Dice que en la huelga de maestros de 1912 actuó junto a Julio Barcos docente de reconocida trayectoria anarquista , y habla de la exoneración de ambos al año siguiente. ${ }^{9}$ Esta misma postura asume Arata ( $\mathrm{s} / \mathrm{d}$ ) cuando menciona a Barcos como activo impulsor de la Liga Nacional de Maestros fundada en 1912 como órgano de representación de los intereses profesionales del magisterio, tarea en la que estuvo secundado por Leonilda Barrancos y Rodolfo Ghioldi. Barcos fue un crítico muy severo del estado de la educación en el país, "sus escritos nutrieron el debate del campo pedagógico argentino y latinoamericano, cuestionando duramente las premisas y las prácticas sobre las que se edificó la pedagogía liberal en las primeras décadas del siglo XX" (Arata, s/d). A pesar de ello, dedicó toda su vida activa al trabajo docente: fue cofundador de escuelas libertarias en la primera década del siglo XX en nuestro país, dio impulso a la fundación de la Liga Nacional de Maestros - tal como ya mencionamos-, fue el creador de la Liga Racionalista Argentina, docente en escuelas oficiales, Inspector del Consejo Nacional de Educación durante el gobierno del radicalismo y viajaba asiduamente por todo el país brindando conferencias (Pita González, 2012). Hacia el final de la década de 1920, Barcos (1927: 25) hablará de tres formas de esclavitud: "en la sociedad actual hay tres esclavos: el proletario, la mujer y el niño. Al primero lo esclaviza el Capital, a la segunda, el hombre y al tercero jtodo el mundo!". Sin lugar a dudas estas fueron las ideas que contribuyeron a moldear el pensamiento de Leonilda Barrancos, que se imprimieron en su sensibilidad y que guiaron su recorrido por la vida. Agreguemos además que es innegable la trama que "enlaza" el progresismo en la educación y el asociativismo docente con fines de defensa gremial.

Al producirse el Primer Congreso Nacional del Niño en Buenos Aires en 1913, Leonilda Barrancos actuó como corresponsal de la Liga Racionalista y publicó un artículo en la revista que la misma editaba en ese momento, La Escuela Popular (año 1, No ${ }_{13}$, 15/11/1913: 5-7). En la parte introductoria encontramos un párrafo en el que ella desnuda sus propias preocupaciones ligadas fuertemente al porvenir de la niñez, pero más que nada es una invitación a mirar a nuestro alrededor y no ser indiferentes ante una realidad que ella sospecha es ignorada por muchos. Dice:

(...) pensamos que no es menester cerrar los ojos y mirar dentro defendiendo el alcázar íntimo de la contemplación extraña, para sentir más y mejor, sino hacer llegar hasta él el dolor que hecho hambre, degeneración o ignorancia, nos pone en cada momento ante la evidencia de ser más "buenos", saliéndonos de nosotros mismos. ¡Angustias de todos los días! Hechos sin trascendencia para los indiferentes, pero que van tejiendo los grandes anhelos de mejoramiento.

"Ser más 'buenos' saliéndonos de nosotros mismos". Ese era el planteo del maestro Vergara seguramente compartido por muchos docentes adherentes a la propuesta de la Liga Racionalista.

Leonilda también destacó la presentación en el Congreso de algunos trabajos y la intrascendencia de otros. Dedicó mayor atención a los de Higiene y Educación, que fueron también los más numerosos. La temática abordada por el Dr. Jacob "Psicopatogenia de los niños retardados y su tratamiento biológico" nos remite a lo que años después ella misma, junto a su esposo Gregorio Bermann, abordarían en Córdoba. En Educación manifestaba haber asistido a todos los debates, destacando la exposición

9 No hemos podido corroborar este dato - no se cita la fuente-, pero nos parece al menos llamativo ya que ella había egresado el año anterior. 
del profesor Nelson "admirable estudio auspiciando la escuela racionalista". Por sus dichos ya estaba arraigada en ella una concepción de la educación escolar que debiera tender a desarrollar la facultad de observar, comparar y descubrir. "Hermoso ideal que ha de hacer de la escuela un centro de desarrollo de la personalidad, habituando al niño a pensar y obrar". También dice que "La escuela laica en manos del Estado sufrió un recio ataque" a pesar de la defensa que de ella hicieron algunos funcionarios. Pero "El profesor Barcos demostró cómo la escuela laica continúa siendo dogmática, pues si se independizó de dogmas religiosos, mantiene los dogmas políticos y perpetúa la rutina".

Dentro del ámbito de la Liga Racionalista, Leonilda Barrancos integró el grupo de personas que brindaban cursos de las más diversas ramas del conocimiento. ${ }^{10}$ Sus preferencias se orientaban hacia la literatura contemporánea, la declamación y el teatro. Por ejemplo, organizó un cuadro filodramático presentado con gran éxito y dio clases de declamación y literatura contemporánea, todo en la sede de Alsina $1565 .{ }^{11}$ Allí fue que Leonilda departió con Gregorio Bermann: de hecho él publicó notas en la revista sobre los temas que eran de su interés tales como Psicología, Ciencia Natural y Extensión Universitaria. En este último exponía su ideal del docente como una persona comprometida, idealista, con convicciones intelectuales y sentimentales, formador de sí mismo, con una ética elevada (La Escuela Popular, $\mathrm{N}^{\circ} 17$ y 18, abril y mayo de 1914).

El escenario político local cambió en cierta manera al ascender el radicalismo al poder en 1916. Quizás lo que varió no fueron tanto las políticas aplicadas en educación como las condiciones de posibilidad de actuación de dirigentes del área que ya venían desenvolviendo su actividad desde tiempo atrás. Puiggrós manifiesta:

En 1918 había un clima de reforma que abarcaba grandes sectores del sistema educativo. En jardines de infantes, escuelas para adultos, primarias y sociedades populares de la Capital y de algunas provincias, los docentes más progresistas desde el punto de vista pedagógico eran también los dirigentes del naciente gremialismo magisterial. (Puiggrós, 2006: 79)

Por esa época ya encontramos a Leonilda en plena actividad docente ${ }^{12}$ en la Escuela Normal Popular de San Martín en Buenos Aires, donde se desempeñó como Directora en algún momento entre 1917 y 1919 (Morello y Morello de Cusano, 1990: 10). La experiencia de estos años hasta que llegó a Córdoba debió haber sido muy enriquecedora y superadora de sus años en la escuela Normal de Paraná en donde se daba un cierto predominio de las llamadas ciencias duras y una menor incidencia de las que serían motivo de su preocupación, Psicología, Filosofía y las artes en general. ${ }^{13}$ Fue hacia fines del siglo XIX y primeras décadas del XX -acentuándose en el período de entreguerras - una época de intensa recepción de las corrientes pedagógicas que venían de Europa, la Escuela Activa, Escuela Nueva o escolanovismo que centraba su mirada en el alumno y en su desarrollo psico-físico. En esta línea, tanto la dirigente

10 Es llamativa la variedad de temáticas abordadas por los cursos de la Liga: Aritmética, Biografías, Anatomía-Fisiología, Lecturas populares, Consideraciones sobre criminalidad, Esperanto, Higiene sexual, Corte y confección, Física, Historia, Canto y Música, Zoología-Botánica, Idioma nacional (La Escuela Popular, año 2, 15/05/1914: 23).

11 Boletín de la Liga Racionalista Argentina, Buenos Aires, 15/11/1914 y marzo de 1915. Aclaramos que la publicación La Escuela Popular apareció entre octubre de 1912 y julio de 1914. A continuación se publicó el Boletín de la Liga Racionalista desde noviembre de 1914.

12 Lugones, Díaz y Romero (2018) mencionan también su paso como docente en la Escuela Normal Popular de Mercedes.

13 Hemos tenido acceso a las asignaturas que se cursaban en esos años en la Escuela Normal de Paraná y a las excelentes calificaciones obtenidas por Leonilda. Ellas eran en $5^{\circ}$ año Práctica, Pedagogía, Literatura, Italiano, Inglés, Geometría, Álgebra, Historia, Anatomía y Fisiología, Psicología F., Dib. Nat. y Práct. C. Nat. (textual). Las asignaturas cursadas en $6^{\circ}$ año eran: Literatura, Cosmografía, Geografía, Legislación, Pedagogía, Práctica, Psicología, Higiene, Inglés, I. Italiano y Topografía (ver Anexo). 
mendocina Florencia Fossatti como Leonilda Barrancos fueron introductoras en la educación argentina de los postulados de Pestalozzi, María Montessori, Decroly y otros innovadores (Puiggrós, 2006: 78). En algún punto, que va más allá de lo cronológico, las historias de vida de estas dos pedagogas se entrelazan: 1919, año convulsionado para la Argentina y para el mundo, encontramos a Florencia (Alvarado, 2016) protagonizando una huelga de docentes en su Mendoza natal y a Leonilda apoyando en nombre de la Federación Universitaria de Buenos Aires una protesta estudiantil en Chivilcoy (Lugones, Díaz, Romero, 2018); y en la década de 1930 ambas fueron dejadas cesantes de sus cargos en la docencia: una en Córdoba (1930) y la otra en Mendoza (1936).

\section{Leonilda en Córdoba}

Con los capitales que hemos enunciado precedentemente, arribó a Córdoba Leonilda Barrancos. Ya se había casado con quien fue el padre de sus tres hijos, Gregorio Bermann (1894-1972), y se radicaron en esta ciudad a mediados de 1921, luego de que él accediera a la cátedra de Medicina Legal en la Facultad de Ciencias Médicas (La Voz del Interior, en adelante $L V I, 01 / 06 / 1921$ ). Además del vínculo marital, había entre ellos una comunidad de pensamiento, una especie de hermandad intelectual, ideológica, que había comenzado en el espacio de la Liga Racionalista Argentina. Pero estos primeros años de estancia en la capital cordobesa estuvieron signados más que nada por la vida familiar, ya que en 1922 nació su hija Silvia, luego su hijo Daniel Gregorio trágicamente fallecido al año y medio de edad, y finalmente su hijo Claudio Santiago en 1926.

No obstante la sabemos participando en la vida social cordobesa desde el lugar del asociacionismo con fines solidarios. Obviamente que estaba ligada junto a su esposo, al grupo de intelectuales que había encabezado y sostenía los principios de la Reforma Universitaria. En 1922, la encontramos impulsando una campaña para la ayuda al pueblo ruso, víctima de una hambruna producida por la combinación de sequía que hizo fracasar la cosecha de trigo y la guerra civil que insumía ingentes esfuerzos. Es así que se forma en Córdoba el "Comité de socorro a las víctimas del hambre en Rusia", organizador de actos diversos. En el mismo existía un Subcomité artístico de cuya dirección formaba parte una única mujer, y ella era Leonilda Barrancos. El Subcomité tenía su sede en el mismo domicilio donde estaba el consultorio particular el Dr. Bermann (LVI, 04/08/1922).

Los intelectuales reformistas entre los que se encontraba Gregorio Bermann, mantenían contactos con pares de otros lugares de América, eran antiimperialistas, antifascistas, levantaban su voz a favor de los presos políticos y promovían la unidad latinoamericana. Leonilda seguramente los acompañó en las peticiones y gestiones que realizaban, tal como ocurrió años después cuando desde muchos lugares del país se levantaron voces en defensa del escritor boliviano Tristán Marof, exiliado en la Argentina y deportado clandestinamente a su país de origen. Numerosas organizaciones se movilizaron para pedir su regreso a la Argentina y su puesta en libertad. Entre las organizaciones que se manifestaron, estaba la Agrupación Femenina Antiguerrera de Cosquín en cuya reunión pronunció un discurso Leonilda Barrancos de Bermann informando del hecho a la junta, la que envió un telegrama al presidente de Bolivia (LVI, 13/03/1936).

Según Bellucci (1986: 52) por estos años se desempeñó como docente en el Liceo Nacional de Señoritas "Manuel Belgrano", del cual fue despedida luego del golpe de estado del 6 de septiembre de 1930. 
Por cierto que se trataba de una persona innovadora, formada al calor de las nuevas tendencias en educación que se daban por esos tiempos en Europa, de las que ella logró ser testigo presencial durante el medio año que permaneció allí en 1930. Ferrari (2012), que dedica su tesis al análisis de las condiciones de posibilidad de la recepción de las ideas de Freud en Córdoba, abundando sobre los aportes de Gregorio Bermann, habla de Leonilda y su pertenencia a la corriente de la Escuela Activa. Se trataba de considerar a la infancia desde una perspectiva más amplia incorporando el valor de los sentimientos "a partir de conceptos tales como sublimación, la labor subconsciente, la represión". Uno de los aportes más trascendentales fue el de ampliar las miradas ya que "el saber médico reorganizaba al espacio y las prácticas educativas", es decir, se incorporaban al campo de la educación los saberes del campo de la salud. En este sentido, se hermana a Leonilda con Conrado Ferrer, ambos alineados por la postura de Gregorio Bermann "quien comprendía a la infancia con una perspectiva psicogenética (...). La higiene mental gestó toda una serie de intervenciones en ese período formativo, buscando la profilaxis de la enfermedad mental y de la criminalidad, sobre todo" (ibídem:335-336).

El campo de la escritura y la publicación no era para las mujeres, aun en la Córdoba reformista, un lugar frecuentado en las primeras décadas del siglo XX. En 1931, la Revista de la Universidad Nacional de Córdoba (RUNC) ${ }^{14}$ publicó un artículo de Leonilda Barrancos titulado "La Reforma Educacional en Austria", donde vuelca sus impresiones sobre el trabajo que allí se estaba realizando. Según su criterio aquel país era uno de los que más había avanzado en el desarrollo de los métodos de la Escuela Activa con un gran aporte de las nuevas tendencias filosóficas, psicológicas y sociales.

Este artículo es una pieza relevante para analizar lo realizado por Leonilda en Córdoba, además de su pensamiento, que lo difundía mediante conferencias. Pone de manifiesto aquí su adhesión a los principios de la Escuela Activa, tal como ya lo había demostrado en su práctica docente anterior. Desde el comienzo critica el tradicionalismo en educación, rescataba los aportes de la cultura griega pero destacaba que hasta ese momento no se había analizado al hombre en su totalidad. Al respecto decía:

El hombre como totalidad viviente se nos aparece al término de las corrientes educacionales que no se proponen moldearlo a semejanza de una imagen pretérita o artificiosa. La escuela activa toma al niño tal como es y no como quisiera que fuera, lo educa de dentro a fuera, en la libertad, en la comunidad, en la armonía del espíritu, la inteligencia y el cuerpo, en la máxima expresión de sus valores.

También rescata los aportes de Freud: "En la psicología freudiana, alcanzan los instintos, sentimientos y labor subconsciente, explicación legítima, no los reprime y desprecia como la antigua pedagogía intelectualista, permite su libre juego y tiende a sublimarlos" (Barrancos, 1931: 104).

En otros párrafos pone de manifiesto cómo la nueva pedagogía "explora" por primera vez zonas antes no tocadas como lo es todo lo relacionado con la creatividad del niño que le permite poner a la vista su sentido de la belleza y su capacidad para crear destacando que el valor más alto de la reforma educativa en Austria reside en lo estético.

También habla enfáticamente de la participación de los docentes, los cuales aparecen comprometidos con la nueva orientación, a quienes se incita a participar mediante el voto en cuestiones educacionales y proponiendo candidatos para ocupar puestos

14 Esta revista había sido creada en 1914 y, como es de suponer, fue en parte caja de resonancia de lo que ocurría al interior de la casa de estudios. El público de estas revistas no solía ser amplio, pero sí cercano a esferas de poder. En este artículo Leonilda critica la política educativa que se había implementado en el sistema educativo argentino; nos parece que más que dirigirse a los maestros se dirige a quienes tienen la posibilidad de decidir los grandes lineamientos de la educación. 
directivos, a ampliar su propio perfeccionamiento y a colaborar en planes y programas (ibídem: 109-111). El Instituto Pedagógico era un centro integral de formación de docentes, donde además de los austríacos, otros países enviaban a sus docentes a perfeccionarse tal como lo había hecho el gobierno chileno recientemente.

Si bien el artículo abarca, como lo indica su título, una profunda mirada y análisis de la reforma educativa en Austria, hay un trasfondo político insoslayable que emerge especialmente cuando se analiza el "cómo" de la reforma, con hincapié en la implementación de la puesta en marcha por la Municipalidad socialista de Viena y la rescata como parte de una evolución social y política, expresión de nuevas formas de pensamiento. Ubica esta reforma dentro del sistema democrático y la construcción de la República. ${ }^{15}$ Ya habían pasado al menos diez años del inicio de la reforma y la garantía de su continuidad estaba dada en que en ella habían participado "el Ministerio, los maestros y el pueblo a favor de la cultura" (ibidem: 105). La dificultad mayor en la continuidad de la misma estaba dada en la oposición parlamentaria encabezada por el partido Social Cristiano, seguramente debido al carácter marcadamente laico de la reforma. La autora no deja de destacar que está hablando de un país castigado por una cruenta guerra desarrollada en su propio territorio y que, no obstante, priorizó la asistencia a la niñez y juventud disminuida fisiológicamente a causa de aquel conflicto y reivindica la direccionalidad que tiene esta reforma, orientada a favorecer especialmente a los sectores populares afectados tanto por la pasada conflagración como por la crisis económica que se estaba viviendo. Pone como ejemplo el uso de:

(...) antiguos internados para la nobleza e hijos de oficiales [que] son convertidos en Institutos para la Nación $\bigotimes$ cuatro para varones y dos para mujeres. Los hijos de los trabajadores concurren a ellos abonando una cuota mensual ínfima y en proporción a los ingresos de los padres o ninguna en caso de indigencia. (ibidem: 106)

Fue una reforma pensada para los obreros de ambos sexos y en ese momento se estaba por implementar "la obligatoriedad para el servicio doméstico y de los obreros que no siguieron cursos en las escuelas de oficios", destacando la existencia de institutos que además de salas para tomar las clases contaban con bibliotecas, salones de fiestas, canchas para deportes, piletas de natación, etc. (ibidem: 108).

En algunos párrafos del extenso artículo introduce comparaciones con el sistema educativo argentino. Por ejemplo, cuando critica la uniformidad y rigidez de la oferta de alternativas para realizar el secundario en nuestro país donde los planes de estudio son pensados, salvo en las dos escuelas universitarias de Córdoba y Buenos Aires, idénticos "como si solo pudiera darse un único tipo de argentinos, con idéntico desarrollo psíquico, con las mismas inquietudes espirituales y el mismo porvenir a que enfrentarse". Tilda a nuestra enseñanza de enciclopédica cuando dice que en Austria la incorporación de la educación estética no es un mero complemento, ni tiende al trabajo productivo o útil, sino que "Despierta en el niño insospechadas potencias creadoras, agita las desconocidas corrientes de su espíritu, que una educación de fuera y libresca no supo revelar" (ibidem: 107-114). Cuenta cómo en Austria los maestros y profesores son formados especializándose en las disciplinas que dictan, habiendo cursado sus especialidades en la universidad o en el Instituto Pedagógico donde dictan sus cátedras los mejores sabios y especialistas en cada asignatura. "Este es sin duda el más grande de sus méritos; nuestras escuelas normales necesitan profesores de esa categoría intelectual" (ibidem: 112).

15 Al finalizar la Primera Guerra Mundial, se produce el desmembramiento del Imperio austro-húngaro y hacia finales de 1918 Austria declara su independencia y se da su propio gobierno adoptando el sistema republicano. 
Su propia experiencia y la comunión intelectual con Gregorio Bermann le había puesto en conocimiento seguramente de la situación de la niñez desvalida en Córdoba en donde "ya desde 1927 se pueden detectar empresas de investigación e intervención médica" (...) "Alrededor de la década del 30, veremos un interés particular por introducir categorías médicas al espacio de la pedagogía y la educación" (Ferrari, 2012: 331). Por eso en su observación de la reforma austríaca destacará el especial tratamiento brindado a los niños desvalidos y anormales [sic] mediante la puesta en marcha de una repartición especial y la creación de institutos ad hoc.

¡Qué pobres deben haberle parecido a Leonilda las escuelas de esa Córdoba conservadora donde ella habitaba! "Cada kindergarten es en Viena como el hogar que edificáramos en el mejor de nuestros sueños con lo mejor de nosotros mismos" (Barrancos, 1931: 110). Eso es lo que vio en aquella ciudad y que reflejó con evidente entusiasmo en su artículo, y tal vez la quimera de reproducirlos fue lo que la llevó en su periplo por América iniciado años después. Con esta expresión de deseos cerró su artículo: "Y fórmense los centros de investigación, los seminarios de pedagogía, porque la escuela nueva, que fatalmente reemplazará a la actual, demandará al maestro mayores conocimientos" (ibidem: 117).

Otra forma de difusión de las ideas era mediante conferencias en donde adquiere valor el contenido de la disertación pero también quien organiza y a quién se dirige. Hemos tenido acceso a la información sobre las que brindaron los esposos BarrancosBermann en Santiago del Estero, organizadas por el grupo local La Brasa compuesto por intelectuales ligados a la Reforma Universitaria de 1918, artistas y profesionales del medio. ${ }^{16}$ Dicho grupo se había constituido en 1925 y, al decir de Guzmán y Glocer (2016), tuvo dos vertientes, una afín a los nacionalistas culturales de Tucumán y Santiago del Estero y otra que militaba en el asociacionismo con contactos con reformistas, socialistas y sectores obreros. Entre el público que asistía a las conferencias, eran numerosos los docentes que en esa época estaban bastante organizados en aquella provincia. ${ }^{17} \mathrm{La}$ revista La Brasa que el grupo editó entre 1927 y 1929 era conocida en Córdoba y tenía a Gregorio Bermann como uno de sus colaboradores.

En consonancia con lo que acabamos de referenciar, no extraña la presencia de Gregorio y Leonilda como conferenciantes en la biblioteca Sarmiento de Santiago del Estero con una temática que estaba interrelacionada. La de Gregorio se tituló "Lo que el hombre debe a su niñez" y la de Leonilda fue "Pedagogía y Psicología". Una medida de la importancia que se brindaba a estos eventos la da el hecho de que dos periódicos locales publicaban la invitación a las conferencias. La Hora los presentaba diciendo:

Para el próximo viernes se anuncia una disertación en nuestra ciudad, bajo el patrocinio de "La Brasa" a cargo del eminente y prestigioso científico profesor doctor Gregorio Berman (sic). Acompañará en su visita al distinguido intelectual su esposa doña Leonilda Barranco (sic) quien como educacionista propulsora de las nuevas corrientes pedagógicas ofrecerá también en interesantes conferencias sugestivos conceptos sobre ese tema. (La Hora, 02/07/1934)

El diario El Liberal se hizo eco de la invitación a ambas conferencias, teniendo palabras muy elogiosas hacia Leonilda, destacando que había perfeccionado sus conocimientos pedagógicos visitando centros de enseñanza de avanzada en sus viajes por Europa y dictado cátedras de literatura, psicología y filosofía en instituciones secundarias de Córdoba (El Liberal, 05/07/1934).

16 En la tesis doctoral mencionada se incluye una fotografía memorable en donde están el Dr. Manuel Martín Fernández, Santiago D. Herrera, la Sra. Leonilda Barrancos, los Dres. Canal Feijoó, Juan Rebosolán, Gregorio Bermann y Mariano R. Paz (Ferrari, 2012: 325).

17 Así lo atestigua la presencia del educador Julio Barcos para brindar una conferencia en 1927 invitado también por La Brasa (Guzmán y Glocer, 2016: 23). 
Dos días después se publicó un resumen de la conferencia que había sido presentada por el Dr. Mariano R. Paz, destacado miembro de La Brasa. ${ }^{18}$ Toda la conferencia giró alrededor de los vínculos entre la Psicología y la Educación y de las corrientes de las cuales era tributaria la educación en la Argentina. Antes de 1900, la más influyente fue la psicología de Herbart que determinó la dirección intelectualista. Otra corriente posterior estuvo marcada por Brentano, se oponía al positivismo y estaba avalada en ese momento por Spranger, quien proponía para la psicología una diferenciación de lo específicamente fisiológico de lo biológico (acotación de campos es el término utilizado). Después se refirió a los aportes contemporáneos de Freud y Adler; el primero, a través del psicoanálisis, "ha permitido aclarar el espíritu del niño y del adolescente colocando en primer plano los instintos sexuales, que no habían sido tenidos en cuenta por la pedagogía eminentemente intelectualista del siglo pasado, que no contemplaba al hombre en su totalidad". Destacó que la divulgación de los postulados de Freud entre los docentes permitiría a estos incorporar la comprensión en especial de los niños difíciles. Respecto de la contribución de Adler dijo que "sus estudios sobre diferentes tipos de niños, los mimados y los maltratados, llevan al conocimiento de la génesis del sentimiento de potencia que en tantos casos guía la conducta del niño y del hombre". Finalmente habló de la dificultad de aplicar entre nosotros los postulados de la Escuela Activa, ya que la carencia de una tradición cultural y filosófica entre los docentes, los vaciaría de sentido. Sería necesaria una sólida base desde el punto de vista teórico, con un cabal conocimiento de la ciencia pedagógica y de los aportes a ella realizados por las especulaciones psicológicas y biológicas. Habló de la reforma educacional en Austria donde, amén de una tradición cultural de mucho tiempo, en ese momento los docentes se formaban en la universidad (El Liberal, 07/07/1934).

La última mención que hemos encontrado de Leonilda en Córdoba es su participación en el Comité de Ayuda al Pueblo Español. ${ }^{19}$ Como tal participó de los actos que se realizaban en la Capital y en diversas localidades del interior. Los objetivos tendían por un lado a recaudar fondos para el socorro y, por otro, a dar a conocer el avasallamiento de que era objeto el gobierno de la República legítimamente constituido. A Leonilda le correspondió ser oradora en Villa María junto a Deodoro Roca $(L V I, 16 / 10 / 1936)$.

\section{A modo de cierre, o apertura para continuar}

Hacia finales de 1936, los esposos Bermann se separaron, hecho que es mencionado por algunos biógrafos pero del cual carecemos de precisiones. Al parecer Leonilda se mudó a Buenos Aires pero dos años más tarde la encontramos en Santiago de Chile adonde había sido invitada por Salvador Allende del cual era amiga. Allí tuvo una interesante actuación dentro del Partido Socialista e integrándose a la actividad pública en el gobierno del Frente Popular.

Cuando comenzamos esta investigación conocíamos muy poco de Leonilda, y en su transcurso aquella figura borrosa ha ido tomando cierta nitidez, al menos en lo que respecta a lo vivido hasta los años 30. Si vamos a coincidir con su esposo Gregorio en que las personas le debemos mucho a nuestra infancia, podríamos decir que ser la mayor de siete hermanos debe haber templado y fortalecido su carácter de tal modo que le permitiera luego completar sus estudios lejos de la casa paterna y tomar una independencia de criterio que no era para nada frecuente en las mujeres de entonces.

18 El Dr. Paz era abogado y alternaba el ejercicio de la profesión con su tarea de educador; fue profesor de Historia, Presidente del Consejo General de Educación y estuvo siempre muy comprometido con la cultura de su provincia.

19 Gregorio Bermann fue uno de los impulsores de la creación de este Comité y unos meses después viajaría a España como parte de las Brigadas Internacionales ocupando el cargo de Comandante Médico. 
Cuando ella llegó a Córdoba ya llevaba un bagaje acumulado en esa riquísima segunda década del siglo XX, alimentado no solo por sus lecturas, sino también por la experiencia laboral, por su participación en pro del asociativismo docente y de los ideales de la Reforma Universitaria que se estaban difundiendo por entonces.

Hacer visible este trayecto de su vida nos ha permitido acceder a algunas de las estrategias que se daban las mujeres para desbordar el ámbito de lo doméstico, que una sociedad misógina les reservaba, y lograr generar hechos de trascendencia en el entrecruce de lo laboral, lo profesional, lo político y la sociabilidad. Así, en esta ciudad trabajó como docente, pero rápidamente se integró al ambiente intelectual que bullía por entonces hermanándose con el resto de Latinoamérica, e imaginamos que su vida intelectual fue creciendo al lado, nunca a la sombra de su esposo, incrementando sus conocimientos acerca de la educación de niños/as y adolescentes. Su viaje a Europa debe haber confirmado sus críticas a una educación tradicionalista, intelectualista, burocrática, represora como la de nuestro país al observar y estudiar de cerca la reforma educacional en Austria.

Por como orientó su vida después de la separación de Bermann, intuimos que su apuesta fue por América (la latina), y por la educación, a la cual dedicó su vida. Sospechábamos que se había dedicado a la política partidaria en el Partido Socialista estando en Córdoba, pero no fue así. Lo que sí está claro es una postura política que implicaba la participación activa, el compromiso, el involucramiento en cuestiones sociales a favor de mayorías que siempre están en minoría a la hora de tomar decisiones. 


\section{Q Bibliografía}

»Alliaud, A. (2007). Los maestros y su historia: los orígenes del magisterio argentino. Buenos Aires/México/Santiago/Montevideo, Granica.

»Alvarado, F. (2016). El Alegato de Florencia Fossatti: claves para una historia de las ideas pedagógicas desde una epistemología feminista. Anuario de la Educación, Vol. 17, № 2.

»Arata, N. (s/d). Julio Barcos. Derivas de un pedagogo intempestivo. Disponible en: https://www.scribd.com/document/209011523/Julio-Barcos-Derivas-de-unpedagogog-intempestivo-Nicolas-Arata-Version-Final

"Arfuch, L. (2002). El espacio biográfico. Buenos Aires, Fondo de Cultura Económica.

» Barcos, J. (1927). Cómo el Estado educa a tu hijo. Buenos Aires, Talleres Gráficos de M. Lorenzo Rañó.

» Barrancos, L. (1913). En La escuela Popular. Órgano de la Liga de Educación Racionalista, año 1, № 13, 15/11/1913: 5-7. Disponible en: http://www. federacionlibertaria.org/archivo-digitalizaciones-LA\%20Escuela\%2oPopular. html

»--------. (1931). La reforma educacional en Austria. Revista de la Universidad Nacional de Córdoba, Año 18, № 3-2, mayo-junio: 103-117. Disponible en: https:// www.revistadelauniversidad.mx/tags/leonilda\%2obarrancos

» Bolufer Peruga, M. (2008). La vida y la escritura en el siglo XVIII. Valencia, Universitat de València.

» Bellucci, M. (1986). Hechos e historias en el mundo femenino. Todo es Historia, № 232, Buenos Aires, septiembre.

»Billorou, M. J. (2016). Mujeres que enseñan no solo en las aulas: docentes en el interior argentino en la primera mitad del siglo XX. Anuario de la Educación, Vol. 17, № 2 .

»Caldo, P. (2018). Tizas y apuntes: costumbres en común. Maestras, libros y prácticas de enseñanza en la Argentina de 1930" En Fiorucci, F. y Rodríguez, L. G. (comps.). Intelectuales de la educación y el Estado: maestros, médicos y arquitectos. Bernal, Universidad Nacional de Quilmes.

»Caldo, P. y Vignoli, M. (2016). Maestras, prácticas género e historia: hacia una historia de la educación en los tiempos de la consolidación de los sistemas educativos. Anuario de la Historia de la Educación, Vol. 17, № 2.

"Carli, S. (2002). Niñez, Pedagogía y Política. Transformaciones de los discursos acerca de la infancia en la historia de la educación argentina entre 1880 y 1955. Buenos Aires, Miño y Dávila.

»Cortés, N. y Freytes, A. (2015). Índice de las primeras mujeres egresadas de la Universidad Nacional de Córdoba, 1884-1950. Córdoba, Editorial de la UNC.

» Ferrari F. J. (2012). Entre el dispositivo psiquiátrico y la disciplina monacal: una historia genealógica de las primeras lecturas de la psicopatología freudiana en Córdoba (1758-1930). Tesis doctoral. Córdoba, Universidad Nacional de Córdoba. 
» Fiorucci, F. (2016). País afeminado, proletariado feminista. Mujeres inmorales e incapaces: la feminización del magisterio en disputa (1900-1920). Anuario de Historia de la Educación, Vol. 17, № 2.

" Guzmán, D. H. y Glocer, S. (2016). Cartas de La Brasa. Patrimonio bibliográfico, 1926-1937. Santiago del Estero, Biblioteca Sarmiento Ediciones.

"La Escuela Popular (1914). № 17 y 18, abril y mayo.

» La Voz del Interior. 01/06/1921; 04/08/1922; 13/03/1936; 16/10/1936. Córdoba.

"Lugones, M.; Díaz, M. y Romero, S. (2018). Leonilda Barrancos: una embajadora reformista. Semblanza y entrevista con Dora Barrancos. Etcétera. Revista del Área de Ciencias Sociales del CIFFyH, № 3. Córdoba, UNC. Disponible en: https://revistas.unc.edu.ar/index.php/etcetera/article/view/22597

»Morello, E. y Morello de Cusano, M. (1990). Apuntes para una Historia de la escuela Normal de San Martín s/d.

» Ossanna, E. y López, M. P. (2004). Educar para argentinizar: una variante cosmopolita. En Biagini, H. y Roig, A. (dirs.). El pensamiento alternativo del siglo XX. Identidad, utopía, integración (1900-1930). Buenos Aires, Biblos.

»Pita González, A. (2012). De la Liga Racionalista a Cómo educa el Estado a tu hijo: el itinerario de Julio Barcos. Revista de Historia, 65-66, enero-diciembre. Disponible en: http://www.revistas.una.ac.cr/index.php/historia/article/view/5068

»Puiggrós, A. (2006). Qué pasó en la educación argentina. Buenos Aires, Galerna.

»Tarcus, H. (2007). Diccionario biográfico de la izquierda argentina. Buenos Aires, Emecé.

» Terigi, F. (1998). El “caso Vergara”. Producción y exclusión en la génesis del sistema educativo argentino. En Puiggrós, A. (dir.). Historia de la educación argentina II. Buenos Aires, Galerna. 


\section{Apéndice documental}
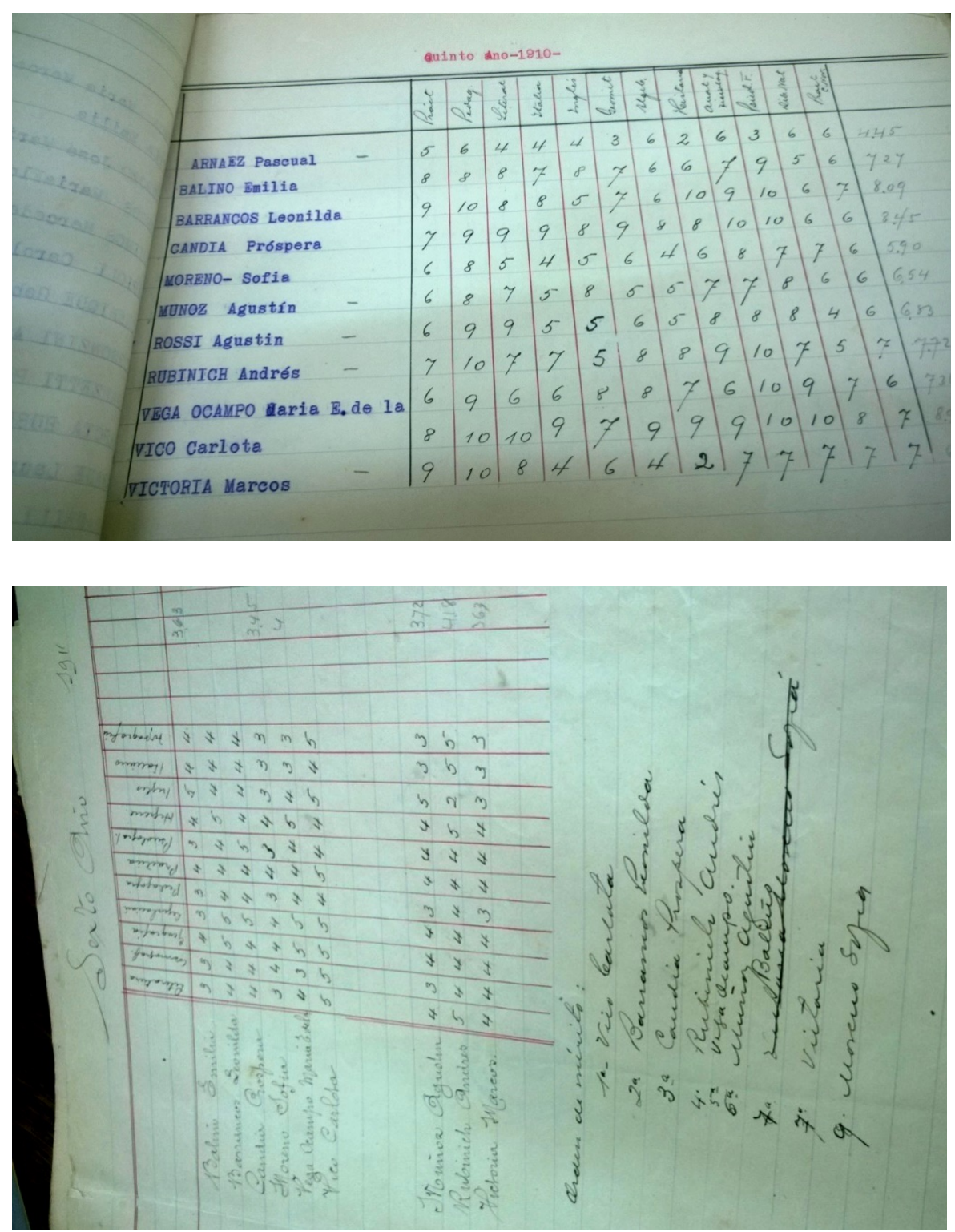

Nómina de alumnos/as y sus calificaciones de quinto año en 1910 y sexto año en 1911 en la Escuela Normal de Paraná. Gentileza del archivo de dicho establecimiento. 


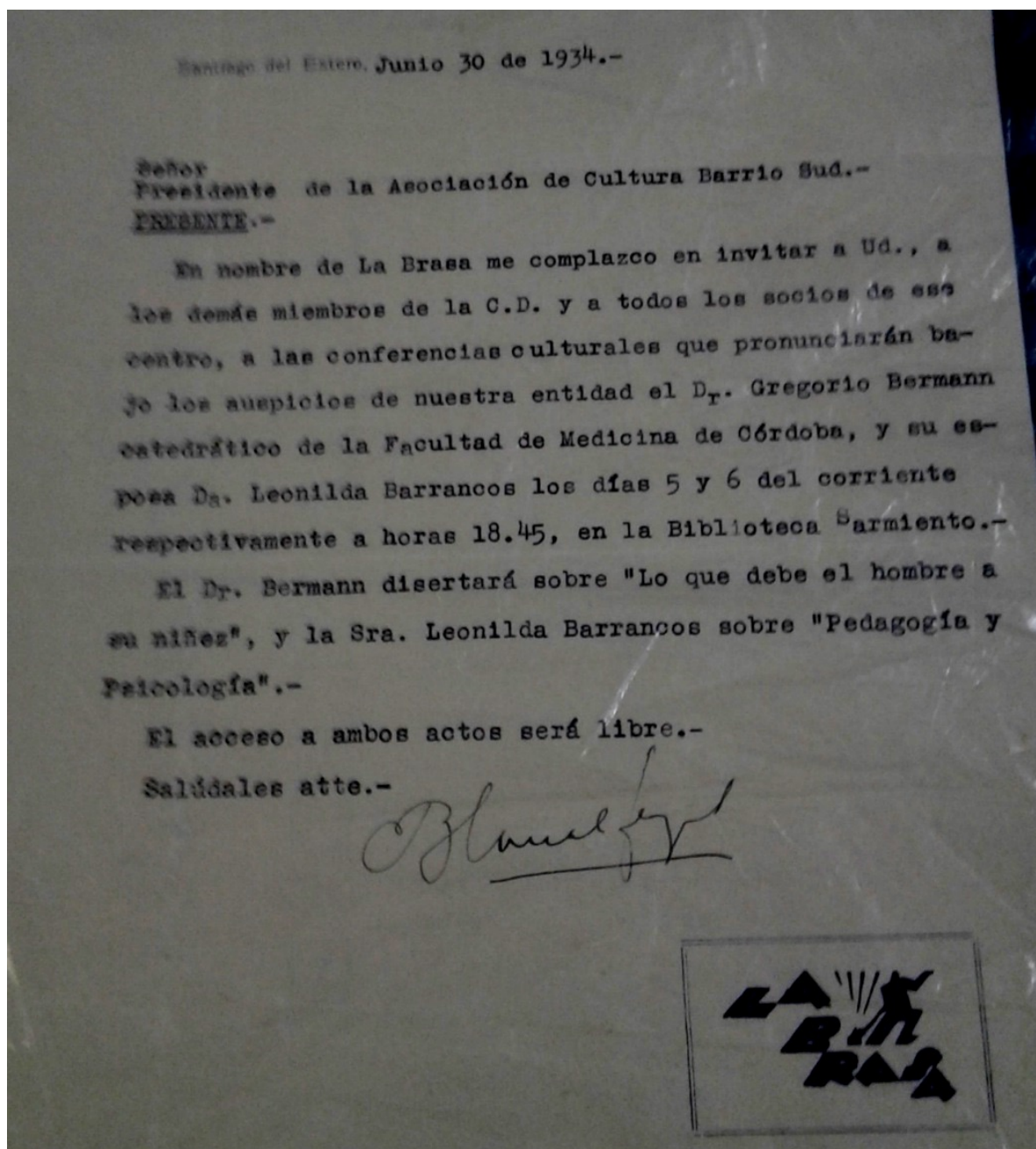

Carta de La Brasa a la Asociación de Cultura Barrio Sur invitando a las conferencias de Gregorio Bermann y Leonilda Barrancos de Bermann. Archivo de la biblioteca Sarmiento de Santiago del Estero. 
